\title{
BASES MOLECULARES DA AÇÃO ANTI-INFLAMATÓRIA DOS ÁCIDOS OLEANÓLICO E URSÓLICO SOBRE AS ISOFORMAS DA CICLO-OXIGENASE POR DOCKING E DINÂMICA MOLECULAR
}

\author{
Wendell Santos Magalhães* e Célia Maria Corrêa \\ Escola de Farmácia, Universidade Federal de Ouro Preto, 35400-000 Ouro Preto - MG, Brasil \\ Ricardo Bicca de Alencastro \\ Instituto de Química, Universidade Federal do Rio de Janeiro, 21949-900 Rio de Janeiro - RJ, Brasil \\ Tanus Jorge Nagem \\ Instituto de Ciências Exatas e Biológicas, Universidade Federal de Ouro Preto, 35400-000 Ouro Preto - MG, Brasil
}

Recebido em 28/10/10; aceito em 11/7/11; publicado na web em 2/9/11

\begin{abstract}
THE MOLECULAR BASIS OF ANTI-INFLAMMATORY ACTION OF THE OLEANOLIC AND URSOLIC ACIDS ON CYCLOOXYGENASE ISOFORMS BY DOCKING AND MOLECULAR DYNAMICS. The triterpenoids oleanolic (OA) and ursolic (UA) acids show non-selective antiinflamatory activity in vitro for cyclooxygenase (COX) isoforms. 3D conformations of OA and UA, with three possible orientations (1, ', and 2) in the active site of isoforms COX, obtained by docking, were submitted to molecular dynamics. The results show that orientation 2 of the OA in COX-2 is more favorable because orientation 1 moved away from the active site. The carboxylate group of OA interact by hydrogen bonds with Ser353 and with Phe357 and Leu359, mediated by water, while hydroxyl in C-3 interact by hydrogen bond, mediated by water, with Tyr385.
\end{abstract}

Keywords: cyclooxygenase; oleanolic/ursolic acid; docking.

\section{INTRODUÇÃO}

As isoformas 1 e 2 da enzima ciclo-oxigenase (COX), uma proteína homodimérica integral de membrana, catalisam a conversão do ácido araquidônico (AA) a prostaglandina $\mathrm{H}_{2}\left(\mathrm{PGH}_{2}\right)$, cujos derivados prostanoides causam efeitos fisiológicos e patológicos, como a inflamação. ${ }^{1}$ COX-1 é constitutivamente expressa em vários tecidos e produz prostanoides necessários à modulação das funções gastrintestinais, renais e à homeostase vascular. COX-2 é considerada induzível porque se expressa em células inflamatórias em resposta a agentes pró-inflamatórios, citocinas, endotoxinas, fatores de crescimento e promotores de tumor, embora esteja presente constitutivamente em regiões glomerulares e em vasos sanguíneos renais, o que demonstra sua importância na manutenção das funções fisiológicas cardiovasculares e renovasculares. ${ }^{2}$ As isoformas COX têm dois sítios ativos, ciclo-oxigenase e peroxidase dependente de heme, que catalisam a conversão de AA a prostaglandina $\mathrm{G}_{2}\left(\mathrm{PGG}_{2}\right)$ e a conversão desta a $\mathrm{PGH}_{2}$, respectivamente. Diversos fármacos anti-inflamatórios não esteroidais (AINEs) inibem o sítio ativo ciclo-oxigenase das isoformas COX (a partir de agora referido simplesmente como "sítio ativo"). Alguns AINEs disponíveis no mercado, como diclofenaco e flurbiprofeno, inibem ambas as isoformas em concentrações semelhantes, enquanto outros, como o celecoxibe, inibem preferencialmente a COX-2 e são classificados como COX-2-seletivos.

Através do estudo de estruturas cristalográficas de isoformas COX complexadas com o AA, com AINEs clássicos e COX-2-seletivos e com ligantes que não se tornaram fármacos como o SC-558, foi possível conhecer a arquitetura do sítio ativo, um longo canal lipofílico cuja entrada é uma constrição feita por Tyr355, Arg120 e Glu524 na superfície da enzima. A cerca de $13 \AA$ de Arg120, no ápice do canal, encontra-se o resíduo catalítico Tyr385, responsável pela conversão de AA em prostaglandina $\mathrm{G}_{2}\left(\mathrm{PGG}_{2}\right)$. Em ambas as isoformas, o canal lipofílico é circundado por Gly526, Ala527, Phe381, Leu384,

*e-mail: magalhaes.wendell@gmail.com
Trp387, Phe513 e Ser530, bem como existe uma cavidade adjacente circundada por Met113, Val116, Val349, Tyr355, Leu359 e Leu531. Em COX-2, os resíduos Leu352, Tyr355, Phe518, Val523 e Ser353 formam uma cavidade lipofílica que é mais acessível nessa isoforma do que em COX-1, devido às posições 434 e 523 serem ocupadas por isoleucina em COX-1 e por valina em COX-2. Anexa à referida cavidade, encontra-se uma cavidade polar circundada por His90, Gln192 e pelo resíduo da posição 513 (Histidina em COX-1, Arginina em COX-2), o que favorece a interação com grupos polares de ligantes em COX-2 porque o grupo guanidina de Arg513 é mais extenso que o anel imidazol de His513., ${ }^{3,4}$

O desenvolvimento dos AINEs seletivos para COX-2, como celecoxibe (Celebra ${ }^{\circledR}$, Pfizer), rofecoxibe (Vioxx ${ }^{\circledR}$, Merck) e lumiracoxibe (Prexige ${ }^{\circledR}$, Novartis) permitiu o tratamento de condições inflamatórias, como a artrite reumatoide e a osteoartrite, sem os efeitos adversos sobre o TGI causados pelos AINEs clássicos. Entretanto, o Vioxx ${ }^{\circledR}$ foi retirado do mercado em 2004 e o Prexige ${ }^{\circledR}$ em 2007, devido ao risco cardiovascular associado ao uso crônico por mais de 18 meses e à formação de metabólitos tóxicos, respectivamente. O celecoxibe ainda é comercializado devido à menor seletividade por $\mathrm{COX}-2$ quando comparado aos outros fármacos COX-2-seletivos. ${ }^{1,5} \mathrm{~A}$ investigação da atividade COX-2-seletiva de novas moléculas naturais, sintéticas e semissintéticas, estruturalmente semelhantes ou não aos coxibes, continua, assim como a avaliação destas no tratamento de outras patologias como câncer e Mal de Alzheimer. ${ }^{6}$

Considerando a biodiversidade brasileira, o pequeno número de estudos acerca do seu potencial farmacoterapêutico e a necessidade de se lançar no mercado outros fármacos COX-2 seletivos, tornase importante avaliar, in silico, a atividade inibitória de moléculas naturais sobre isoformas COX. Os ácidos oleanólico (Ácido 3-betahidróxi-olea-12-eno-28-oico) e ursólico (Ácido 3-beta-hidróxi-urso12-eno-28-oico), AO e AU (Figura 1), são triterpenoides encontrados em plantas utilizadas na medicina oriental com diversas aplicações terapêuticas. ${ }^{7}$ A atividade anti-inflamatória de AO e AU foi avaliada através de estudos in vitro, em que se verificou, conforme valores de 


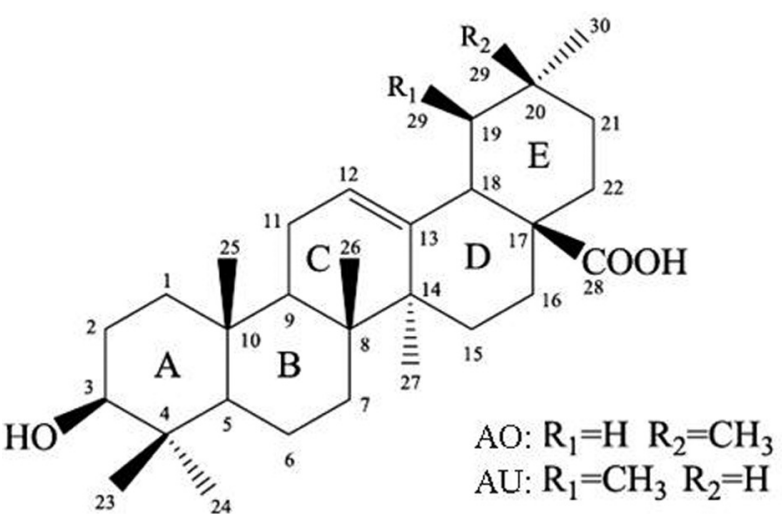

Figura 1. Estrutura química de $A O$ e $A U$

$\mathrm{IC}_{50}$ (inhibitory concentration $50 \%$ - concentração inibitória 50\%) inibição não seletiva das isoformas COX-1 ( $\operatorname{IC}_{50} 380$ e $210 \mu \mathrm{M}$, respectivamente) e COX-2 ( $\mathrm{IC}_{50} 295$ e $130 \mu \mathrm{M}$, respectivamente). ${ }^{8}$ Neste trabalho, objetivou-se estudar, por docking e dinâmica molecular, as interações dos triterpenoides $\mathrm{AO}$ e $\mathrm{AU}$ com as isoformas COX-1 e COX-2.

\section{PARTE EXPERIMENTAL}

\section{Preparação das estruturas de isoformas COX e dos ligantes para o docking}

As estruturas cristalográficas de isoformas COX complexadas com os respectivos ligantes (Figura 2), obtidas do PDB (Protein Data Bank $)^{9}$ sob os códigos de acesso 1CQE $(\mathrm{R}=3,10 \AA),{ }^{10} 1 \mathrm{DIY}(\mathrm{R}=3,00$ $\AA),{ }^{11} 2 \mathrm{OYE}(\mathrm{R}=2,85 \AA),{ }^{12} 2 \mathrm{OYU}(\mathrm{R}=2,70 \AA)^{12}$ e $3 \mathrm{KK} 6(\mathrm{R}=2,75 \AA),{ }^{13}$ referentes à COX-1 de origem ovina, e $1 \mathrm{CX} 2(\mathrm{R}=3,00 \AA),{ }^{3} 3 \mathrm{PGH}$ $(\mathrm{R}=2,50 \AA),{ }^{3} 4 \mathrm{COX}(\mathrm{R}=2,90 \AA)^{3}$ e $1 \mathrm{PXX}(\mathrm{R}=2,90 \AA),{ }^{14}$ referentes à COX-2 de origem murina, foram preparadas no programa SwissPDBViewer $4.0^{15}$ gerando arquivos de monômeros contendo somente os resíduos de aminoácidos e o grupo heme e arquivos contendo somente os ligantes cristalográficos anteriormente complexados aos referidos monômeros. As estruturas dos sítios ativos de COX-1 e COX-2 humanas são muito semelhantes às estruturas dos sítios ativos de COX-1 ovina e COX-2 murina, disponibilizados no PDB, porque há aproximadamente 60 e $87 \%$ de identidade de sequência nas estruturas da proteína completa e do sítio ativo, respectivamente, o que permite a utilização das estruturas cristalográficas citadas. ${ }^{3,16} \mathrm{Os}$ ligantes cristalográficos, $\mathrm{AO}$ e AU foram desenhados no programa PC Spartan Pro ${ }^{17}$ mantendo os grupos carboxilatos ionizados, conforme o pH fisiológico, e minimizados pelo modelo mecânico-quântico semiempírico Austin Model 1 (AM1) ${ }^{18}$ no mesmo programa.

\section{Docking de ligantes cristalográficos, AO e AU com monômeros de isoformas COX}

Os monômeros de isoformas COX foram submetidos a tratamento no programa AutoDockTools 1.5.2, ${ }^{19}$ adicionando-se hidrogênios polares e cargas Gasteiger, ${ }^{20}$ mantendo-se a estrutura rígida e todos os resíduos de histidina protonados. Os ligantes também foram submetidos ao tratamento nesse programa mantendo-se todas as ligações torcionáveis flexíveis e adicionando-se cargas Gasteiger. As malhas tridimensionais de afinidades ( $\mathrm{grid}$ ) dos monômeros foram calculadas pelo programa AutoGrid $4,{ }^{21}$ centradas no ligante cristalográfico com grid de 60x60x60 e distância entre pontos de 0,375 Å. Os dockings de ligantes cristalográficos $\mathrm{AO}$ e $\mathrm{AU}$, com monômeros de isoformas COX, foram executados pelo programa AutoDock $4,{ }^{21}$ que utiliza o algoritmo genético Lamarckiano (LGA - Lamarckian Genetic Algori-

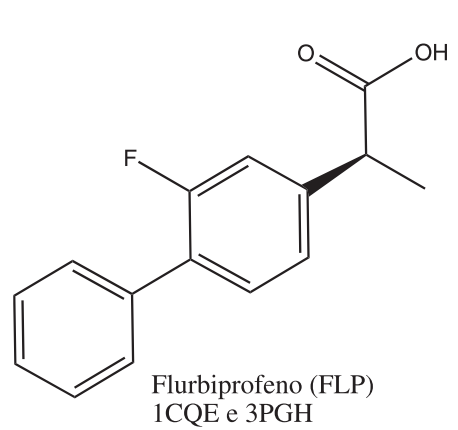
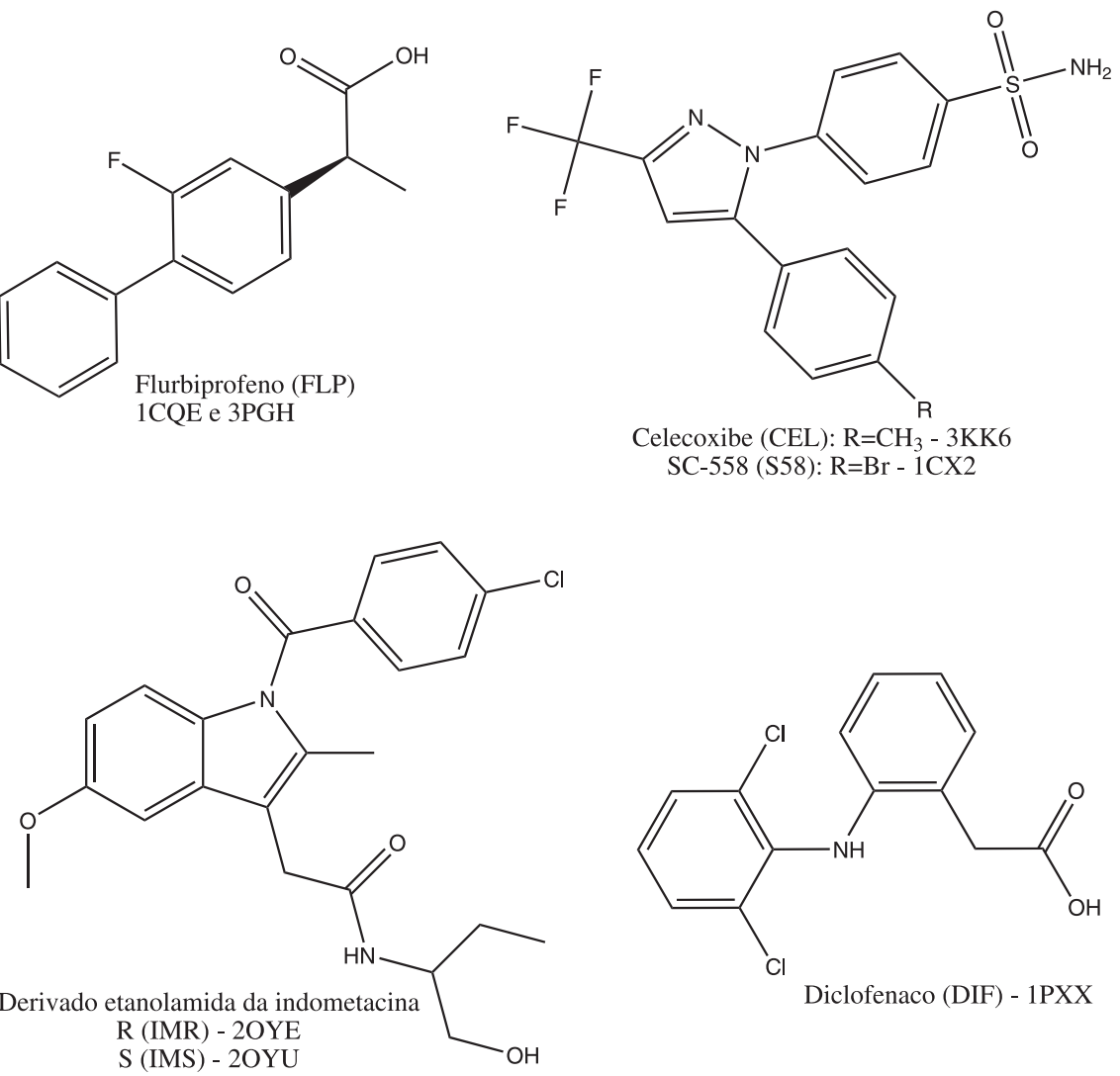
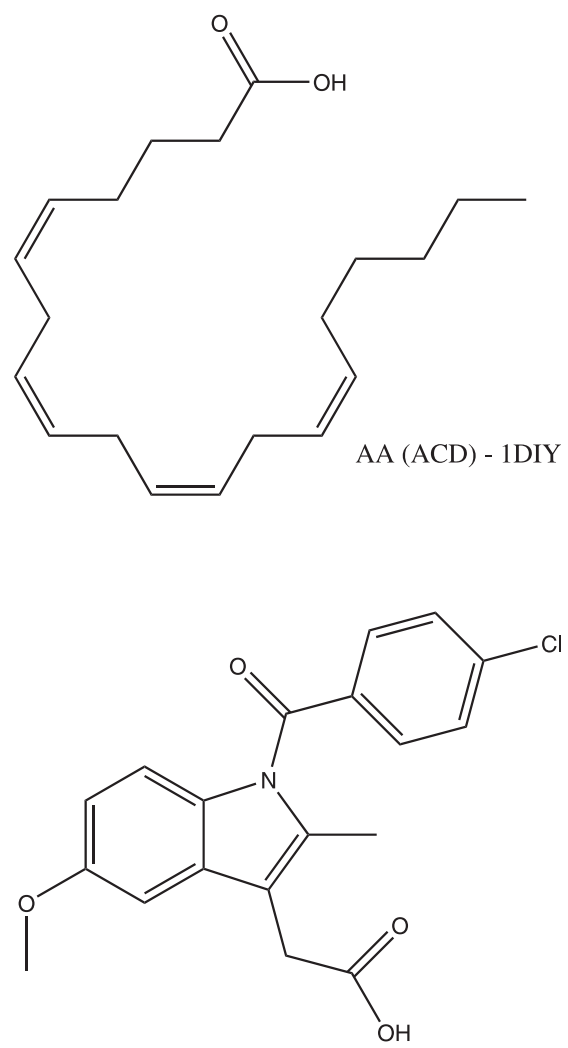

Indometacina (IMN) - 4COX

Figura 2. Estruturas químicas dos ligantes complexados às estruturas cristalográficas de isoformas COX 
thm) ${ }^{22}$ classificado como algoritmo de busca estocástica ou randômica, e função de pontuação (scoring) empírica para calcular a energia livre de binding $\left(\Delta \mathrm{G}_{\text {bind }}\right)$ dos complexos propostos. ${ }^{23} \mathrm{O}$ protocolo do LGA utilizou uma população inicial de 150 indivíduos, no máximo 27.000 gerações e 2.500 .000 avaliações de energia, taxa de mutação 0,02 , taxa de permutação 0,8 , taxa de elitismo 1,0 , produção de 20 soluções para cada docking e demais parâmetros definidos pelo programa automaticamente. Para o cálculo dos desvios quadráticos médios (RMSD - root mean square deviation) dos ligantes cristalográficos minimizados obtidos do docking em relação àqueles obtidos da estrutura cristalográfica, foi utilizado o programa Surflex 2.11. ${ }^{24}$ Foram considerados validados os dockings cujos ligantes apresentaram RMSD menor que $2,0 \AA .{ }^{25} \mathrm{O}$ AutoDock 4 ordenou as soluções conforme o $\Delta \mathrm{G}_{b i n d}$ e agrupou-as em clusters (conjuntos) conforme o RMSD, medido em relação à solução mais estável de cada cluster. Para a visualização gráfica dos resultados dos dockings foram utilizados os programas AutoDockTools 1.5.2 e Discovery Studio Visualizer 2.5.5. ${ }^{26}$

\section{Dinâmica molecular e redocking de AO e AU com monômeros obtidos de complexos equilibrados}

Após a seleção para DM dos complexos de monômeros de COX com AO e AU provenientes do docking, foram geradas as topologias dos monômeros no programa Gromacs ${ }^{27}$ utilizando campo de força GROMOS96 versão $45 \mathrm{~A} 3,{ }^{28}$ reparametrizado a partir da versão $43 \mathrm{~A} 1^{29}$ e dos ligantes no ProDrg ${ }^{30}$ utilizando campo de força GROMOS96 e atribuição total de cargas, que foram substituídas pelas cargas Hartree-Fock 6-31G calculadas com auxílio do programa Gaussian $03 \mathrm{~W}$ versão 6.0, ${ }^{31}$ após minimização de energia pelo referido método. Em seguida, os complexos monômero-ligante foram solvatados explicitamente por água do tipo SPC (simple point charge $)^{32}$ numa caixa cúbica utilizando condições periódicas de contorno, com distância de $1 \mathrm{~nm}$ entre o soluto e a superfície da caixa. Contraíons sódio foram adicionados aos sistemas de forma a neutralizar as cargas, conforme requisitado pelo programa. Todos os sistemas foram submetidos à minimização de energia usando o algoritmo Steepest Descent seguido por Gradiente Conjugado e, em seguida, foram utilizados como ponto de partida para as simulações de DM, conforme relatado a seguir. ${ }^{33}$

Nos experimentos de DM, o método LINCS (Linear Constraint Solver $)^{34}$ foi aplicado na restrição de ligações covalentes do soluto e da água para permitir um passo de integração de 2 fs. As interações eletrostáticas foram calculadas pelo método PME (Particle-Mesh Ewald) ${ }^{35}$ A temperatura e a pressão do sistema foram mantidas constantes, através do acoplamento de todas as espécies dos sistemas a banhos externos de temperatura e pressão. ${ }^{36} \mathrm{~A}$ termalização compreendeu o aquecimento gradativo dos sistemas de 10 a $310 \mathrm{~K}$, mantendo flexíveis somente as estruturas do solvente com os objetivos de inseri-lo nas cavidades da macromolécula e de evitar deformações na estrutura desta; nesse processo, os sistemas foram mantidos a $10,50,100,150,200$ e $250 \mathrm{~K}$ durante 20 ps cada e a $310 \mathrm{~K}$ por 30 ps, totalizando 150 ps de termalização. As etapas de equilibração e produção foram feitas na temperatura de equilíbrio de $310 \mathrm{~K}$ até que fossem completados 15.000 ps. Adicionalmente, para verificar a possibilidade de interações favoráveis que necessitassem superar barreiras de energia, os sistemas foram aquecidos a $410 \mathrm{~K}$ durante 50 ps e mantidos novamente a $310 \mathrm{~K}$ durante $150 \mathrm{ps}$, totalizando 15.200 ps (15,2 ns) de simulação por DM.

As análises de estabilização dos sistemas consideraram os gráficos de RMSD produzidos pelo Gromacs a partir da comparação entre a estrutura inicial minimizada e a estrutura obtida ao longo da trajetória. Estando os sistemas equilibrados, foram analisadas as interações receptor-ligante. As interações por ligação de hidrogênio observadas nos complexos obtidos a 15,2 ns foram avaliadas quanto à distância H“-.Aceptor (máximo de 2,2 Å) e ao ângulo HÂY (H, átomo de hidrogênio; A, átomo aceptor; Y, átomo ligado por covalência ao átomo aceptor), sendo que foram consideradas estáveis as interações cujos ângulos HÂY medidos se aproximaram do ângulo HÂY ideal, relacionado à hibridação do átomo aceptor. ${ }^{37}$

Foram identificadas também as posições de aproximação entre os sítios reativos de $\mathrm{AO}$ e AU, passíveis de modificação por semissíntese, e a cavidade de seletividade de ambas isoformas que é mais acessível em COX-2 do que em COX-1, pois isso é relevante para o planejamento de inibidores COX-2-seletivos. Para o cálculo do $\Delta \mathrm{G}_{\text {bind, }}$, foram feitos os redockings de $\mathrm{AO}$ e $\mathrm{AU}$ com os monômeros obtidos a 15,2 ns contendo todas as moléculas de água presentes no sítio. A metodologia empregada nesses redockings seguiu os mesmos parâmetros daquela relatada para os dockings iniciais com os monômeros obtidos do PDB, mas a geração dos grids foi feita com os ligantes AO e AU extraídos dos complexos obtidos a 15,2 ns.

\section{RESULTADOS E DISCUSSÃO}

\section{Docking dos monômeros rígidos de isoformas COX obtidos do PDB com os respectivos ligantes}

Os valores de $\Delta \mathrm{G}_{\text {bind }}$ obtidos foram considerados satisfatórios, mas não podem ser comparados entre si devido a limitações da função de pontuação. ${ }^{38}$ Esses valores também não podem ser comparados com dados experimentais devido à falta destes na literatura, pois apenas os valores de $\mathrm{IC}_{50}$ de alguns ligantes cristalográficos para isoformas $\mathrm{COX}$ estão relatados e variam conforme o método experimental empregado.

A Figura 3 mostra um desvio na relação entre o RMSD e o número de ligações torcionáveis dos ligantes para os dockings de 4COX com indometacina, de 2OYE e 2OYU com os derivados etanoamidas e de 1DIY com o substrato AA. Entretanto, esse desvio pode ser considerado normal ao se considerar a resolução moderada ou baixa das estruturas cristalográficas, que contribui para uma incerteza considerável do posicionamento dos átomos do ligante cristalográfico no complexo original. Assim, considerando os valores de RMSD obtidos, verifica-se que o método utilizado é robusto, especialmente para ligantes pouco flexíveis, como o são AO e AU, que têm apenas duas ligações torcionáveis.

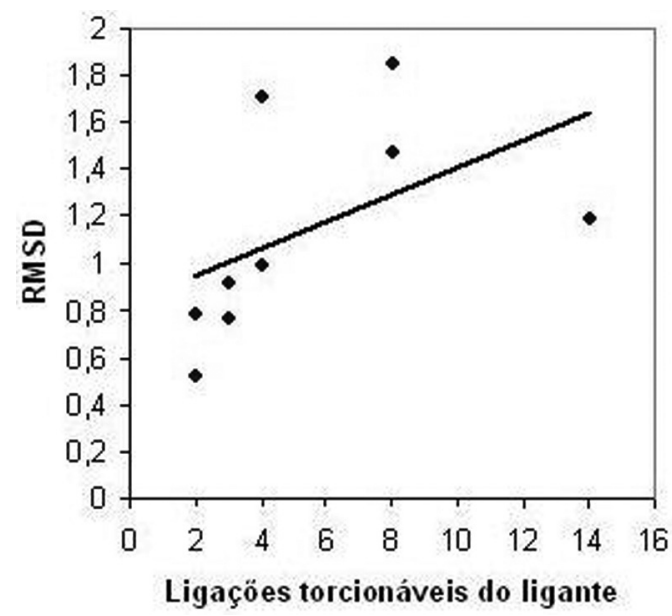

Figura 3. Correlação do número de ligações torcionáveis dos ligantes como RMSD $(\AA)$ conforme dados da Tabela $1 S$ (material suplementar). O coeficiente de correlação R equivale a 0,5

\section{Dockings dos monômeros rígidos de isoformas COX com os ligantes AO e AU}

Os dockings de monômeros de isoformas $\mathrm{COX}$ com $\mathrm{AO}$ e $\mathrm{AU}$ 
produziram complexos em que esses ligantes se posicionaram no sítio com orientações e conformações distintas, o que demonstrou o quanto a estrutura rígida do monômero, moldada pelo ligante cristalográfico, influiu sobre o posicionamento dos ligantes. As orientações de AO e AU nos sítios das isoformas COX foram denominadas 1, 1' e 2 conforme Figura 4. Foram observadas variações no direcionamento das ligações flexíveis e no posicionamento dos grupos funcionais das soluções dentro do sítio, ainda que classificadas dentro de um mesmo grupo como orientação 1, 1' ou 2. Dessa forma, a seleção dos complexos que seriam submetidos à DM considerou as orientações de $\mathrm{AO}$ e $\mathrm{AU}$ e os posicionamentos dos seus grupos funcionais nos sítios das isoformas COX. Foram selecionados os complexos de AO e AU produzidos a partir dos dockings com os monômeros obtidos de 1DIY, 2OYE, 3PGH e 4COX, pois os dockings produzidos com os demais monômeros de COX forneceram complexos semelhantes a estes selecionados.
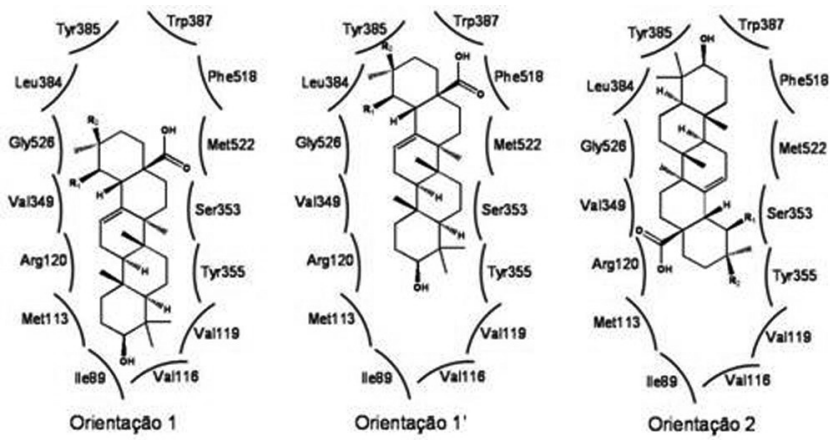

Figura 4. Orientações de $A O$ e AU nos sítios ativos das isoformas $C O X$, obtidas dos dockings com monômeros rígidos

Complexos de $\mathrm{AO}$ e AU com COX-1: os dockings de $\mathrm{AO}$ e $\mathrm{AU}$ com 1DIY produziram orientações 1, em que as hidroxilas em C-3 se aproximaram de Met113 e Val116 e os grupos carboxilato se aproximaram de Met522 e Gly526; orientações 2, em que as hidroxilas em C-3 se aproximaram de Ser530 e Phe381 e os grupos carboxilato, de Phe518 e Leu352. O docking 2OYE-AU produziu orientações 1 semelhantes àquelas relatadas para os complexos de $\mathrm{AO}$ e $\mathrm{AU}$ com 1DIY, e orientações 2, em que a hidroxila em C-3 se aproximou de Val349 e Ser353 e o grupo carboxilato, de Val116 e Arg120. O docking 2OYE-AO produziu orientações 1, em que a hidroxila em C-3 se aproximou de Val119 e Ile89 e o grupo carboxilato, de Ser353 e Leu359.

Complexos de $\mathrm{AO}$ e AU com COX-2: o docking 3PGH-AO produziu orientações 1 equivalentes àquelas obtidas dos dockings de $\mathrm{AO}$ e AU com 1DIY, enquanto o docking 4COX-AO produziu orientações 2, em que as hidroxilas em C-3 se aproximaram de Trp387, Tyr385 e Leu384 e os grupos carboxilato, de Ser353 e Val349. O docking $4 \mathrm{COX}-\mathrm{AU}$ produziu orientações 2,1 e 1 '. A orientação 2 interagiu de forma ligeiramente diferente daquela relatada para o complexo 4COX-AO, pois a hidroxila em C-3 se aproximou de Leu384, Phe381 e Tyr385 e o carboxilato, de Leu359 e Ser353. Na orientação 1', a hidroxila em C-3 aproximou-se de Tyr355 e o carboxilato, de Leu352, Tyr348 e Trp387; na orientação 1, a hidroxila em C-3 aproximou-se de Met113 e Val116 e o carboxilato, de Phe518, Met522 e Ala527.

\section{Dinâmica molecular dos complexos de AO e AU com monômeros de isoformas COX}

Conforme a Figura 1S (material suplementar), as cadeias principais de todos os monômeros complexados a AO e AU estabilizaram-se próximo ao intervalo de 4 a 7,5 ns. Foram observadas variações sutis de RMSD nesses gráficos, mas elas não podem ser relacionadas a
$\mathrm{AO}$ e AU pois se referem aos carbonos-alfa da cadeia principal do monômero. Devido a esses ligantes serem estruturalmente muito semelhantes e ocuparem um sítio ativo anteriormente ocupado pelo ligante cristalográfico, tendem a causar modificações mais pronunciadas nas cadeias laterais dos resíduos do sítio do que na cadeia principal do monômero durante a DM.

As análises das interações receptor-ligante foram feitas aos 8, 9, 10 e 12 ns, não tendo sido observadas diferenças na flutuação dos ligantes e das cadeias laterais dos monômeros a partir de $10 \mathrm{~ns}$ de simulação, o que justificou o prolongamento da trajetória até $15 \mathrm{~ns}$ a fim de garantir um resultado mais confiável. Como a hidroxila em C-3 dos ligantes não interagiu por ligação de hidrogênio com resíduos de aminoácidos próximos em alguns complexos, possivelmente devido a barreiras energéticas que deveriam ser superadas para modificação dos graus de liberdade dos resíduos, todos os sistemas finais foram simulados por mais 50 ps a $410 \mathrm{~K}$ e por 150 ps a $310 \mathrm{~K}$, sem que ocorressem alterações, totalizando 15,2 ns de simulação.

Em todos os complexos obtidos da DM a 15,2 ns foram verificadas interações por ligação de hidrogênio consideradas estáveis, conforme a distância e ângulo HÂY. Os ligantes interagiram dessa forma com resíduos de aminoácidos que são conservados em ambas as isoformas e interagem com o substrato AA, como Tyr385, ou com inibidores, como Arg120, Tyr355, Ser530 e His90; este último resíduo é muito importante na interação com inibidores seletivos da COX-2. Em todos os complexos obtidos da DM foi verificada, também, a presença de moléculas de água próximas aos grupos polares dos ligantes. Apesar de o sítio das isoformas COX ser lipofílico, moléculas de água exercem um papel fundamental nas interações com vários inibidores de COX, seletivos ou não, inclusive por mediarem interações por ligação de hidrogênio entre o inibidor e o receptor. ${ }^{39,40}$

\section{Complexos de AO com COX-1 provenientes da DM}

Conforme a Tabela 1, no complexo da orientação 1 de AO com 1DIY foram observadas interações por ligação de hidrogênio do carboxilato do ligante com a hidroxila de Ser530 e da hidroxila em C-3 do ligante com a carbonila de Leu357. No complexo da orientação 1 de AO com 2OYE foram observadas interações por ligação de hidrogênio do carboxilato do ligante com o anel imidazol de His90 e com a hidroxila de Ser353, mediadas por água, com a amina de Ser353 (interação fraca, conforme o ângulo HÂY) e duas moléculas de água. No complexo da orientação 2 de AO com 1DIY foram observadas duas interações fracas (conforme o ângulo HÂY) por ligação de hidrogênio do carboxilato do ligante com a hidroxila de fenol de Tyr355, que provavelmente correspondem a uma interação forte com a região de caráter negativo localizada entre os dois átomos de oxigênio do grupo carboxilato. Foram observadas também interações por ligação de hidrogênio do carboxilato do ligante com o grupo guanidina de Arg120 e com uma molécula de água. Dentre os complexos de AO com COX-1, apenas no complexo 2OYE-AO o carboxilato do ligante se aproximou da cavidade de seletividade (Ser353, His90) acessível em COX-2 e considerada inacessível em COX-1 pelos fármacos COX-2-seletivos, apesar de alguns ligantes já terem demonstrado interações com essa cavidade na isoforma 2OYE, em que é mais acessível. ${ }^{12}$

Complexos de AO com COX-2 provenientes da DM

Conforme a Tabela 1, no complexo com $3 \mathrm{PGH}$, o carboxilato de AO (orientação 1) interagiu por ligações de hidrogênio com o carboxilato de Glu524 e a hidroxila de Tyr355, mediadas por água, e com Ser353. A hidroxila em C-3 desse ligante interagiu por ligação de hidrogênio com moléculas de água próximas à superfície da proteína. O complexo de 4COX com AO (orientação 2) mostrou interações por ligação de hidrogênio do carboxilato do ligante com a carbonila de Phe357 e amina de Leu359, mediadas por água, e com a hidroxila de Ser353, bem como fraca interação 
Tabela 1. Interações por ligação de hidrogênio dos complexos de AO com COX-1 e COX-2, provenientes da $\mathrm{DM}_{\text {, e }} \Delta \mathrm{G}_{b i n d}\left(\mathrm{Kcal}_{\mathrm{mol}}{ }^{-1}\right)$ calculados pelo AutoDock 4

\begin{tabular}{|c|c|c|c|c|}
\hline $\begin{array}{l}\text { Orientação de AO - PDB } \\
\Delta \mathrm{G}_{\text {bind }} \text { redocking }\left(\mathrm{Kcal} \mathrm{mol}^{-1}\right)\end{array}$ & $\begin{array}{l}\text { Interação por ligação } \\
\text { de hidrogênio }\end{array}$ & $\begin{array}{l}\text { Distância } \\
\text { H*A }(\AA)\end{array}$ & $\begin{array}{l}\text { Ângulo } \\
\text { HÂY }_{\text {obs }}\end{array}$ & $\begin{array}{l}\text { Ângulo } \\
\mathrm{HÂAY} \\
\text { prev }\end{array}$ \\
\hline Orientação 1 - 2OYE (COX-1) -11,11 & 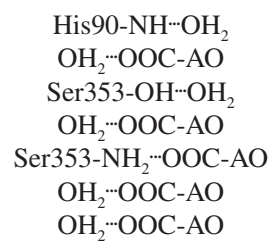 & $\begin{array}{l}1,9 \\
1,6 \\
1,8 \\
1,6 \\
2,2 \\
2,1 \\
1,8\end{array}$ & $\begin{array}{c}114,8^{\circ} \\
108,9^{\circ} \\
99,7^{\circ} \\
108,9^{\circ} \\
164,1^{\circ} \\
167,4^{\circ} \\
104,8^{\circ}\end{array}$ & $\begin{array}{c}109,5^{\circ} \\
120^{\circ} \\
109,5^{\circ} \\
120^{\circ} \\
120^{\circ} \\
120^{\circ} \\
120^{\circ}\end{array}$ \\
\hline Orientação 1 - 1DIY (COX-1) -12,39 & 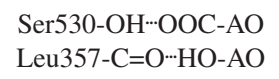 & $\begin{array}{l}1,9 \\
1,8\end{array}$ & $\begin{array}{l}101,3^{\circ} \\
139,8^{\circ}\end{array}$ & $\begin{array}{l}120^{\circ} \\
120^{\circ}\end{array}$ \\
\hline Orientação 2 - 1DIY (COX-1) -13,37 & 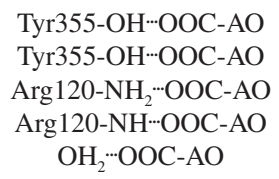 & $\begin{array}{l}2,1 \\
2,1 \\
1,6 \\
2,1 \\
1,8\end{array}$ & $\begin{array}{c}74,3^{\circ} \\
75,1^{\circ} \\
158,4^{\circ} \\
126,4^{\circ} \\
140,6^{\circ}\end{array}$ & $\begin{array}{l}120^{\circ} \\
120^{\circ} \\
180^{\circ} \\
120^{\circ} \\
120^{\circ}\end{array}$ \\
\hline Orientação 1 - 3PGH (COX-2) -9,27 & 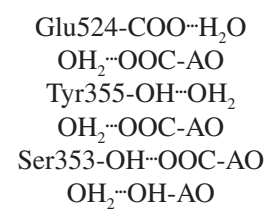 & $\begin{array}{l}1,9 \\
1,9 \\
1,7 \\
1,9 \\
1,9 \\
2,2\end{array}$ & $\begin{array}{c}152,8^{\circ} \\
104,3^{\circ} \\
107,4^{\circ} \\
104,3^{\circ} \\
174,0^{\circ} \\
42,5^{\circ}\end{array}$ & $\begin{array}{c}180^{\circ} \\
120^{\circ} \\
109,5^{\circ} \\
120^{\circ} \\
180^{\circ} \\
109,5^{\circ}\end{array}$ \\
\hline Orientação 2 - 4COX (COX-2) -12,06 & 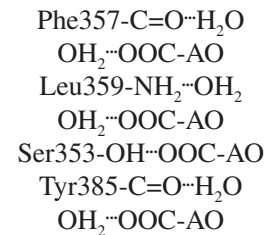 & $\begin{array}{l}1,8 \\
1,6 \\
1,9 \\
1,6 \\
1,9 \\
1,8 \\
2,1\end{array}$ & $\begin{array}{c}138,3^{\circ} \\
144,7^{\circ} \\
101,0^{\circ} \\
144,7^{\circ} \\
110,3^{\circ} \\
130,8^{\circ} \\
88,7^{\circ}\end{array}$ & $\begin{array}{c}120^{\circ} \\
120^{\circ} \\
109,5^{\circ} \\
120^{\circ} \\
120^{\circ} \\
120^{\circ} \\
120^{\circ}\end{array}$ \\
\hline
\end{tabular}

HÂA $\mathrm{obs}_{\text {e }} \mathrm{HÂ} \mathrm{Y}_{\text {prev }}$ referem-se, respectivamente, aos ângulo HÂY observado e previsto conforme a hibridação do átomo A, sendo que H (átomo de hidrogênio), A (átomo aceptor) e Y (átomo ligado por covalência ao aceptor).

por ligação de hidrogênio mediada por água da hidroxila em C-3 do ligante com a carbonila de Tyr385. O grupo carboxilato do ligante aproximou-se da entrada da cavidade de seletividade (Ser353). A visualização dos complexos mostrou que ambas as orientações do ligante, apesar de estarem invertidas no sítio, têm o grupo carboxilato próximo aos resíduos da base como Tyr355 e Ser353. Isso ocorreu porque no complexo formado com 3PGH o ligante se distanciou muito do ápice do sítio, ocupando uma extensão menor do canal lipofílico, o que é uma desvantagem para a inibição da enzima e indica a possível saída do ligante do sítio ativo durante a simulação. Por isso, pode-se afirmar que a orientação 2 de AO (Figura 5) é energeticamente mais favorável do que a orientação 1 no sítio de COX-2.

\section{Complexos de AU com COX-1 provenientes da DM}

Conforme a Tabela 2, os complexos de 1DIY e 2OYE formados com as orientações 1 de AU, apesar de terem demonstrado interações distintas no docking inicial feito com os monômeros obtidos do PDB, convergiram para interações semelhantes durante a simulação de DM. Esse fato mostrou que as interações obtidas nos dockings iniciais podem não ser corretas, o que demonstra a importância de se combinar os métodos de docking e DM em estudos de interações ligante-receptor. Em ambos os complexos citados, o carboxilato de AU interagiu por ligação de hidrogênio com a hidroxila de fenol de Tyr385 e com uma molécula de água, além de ter interagido com as hidroxilas de Tyr348 e Ser530 nos complexos formados com 1DIY e 2OYE, respectivamente. No complexo da orientação 1 de AU com 2OYE, a hidroxila em C-3 do ligante interagiu por ligação de hidrogênio com uma molécula de água presente na base do sítio, ausente no complexo formado com 1DIY. Nos complexos de 1 DIY e 2 OYE formados com as orientações 2 de AU foram verificadas interações muito diferentes entre si, conforme já havia sido verificado no docking inicial devido aos posicionamentos distintos do ligante. Em 2OYE, o carboxilato da orientação 2 de AU interagiu por ligação de hidrogênio mediada por água com os grupos guanidina de Arg79, $\operatorname{Arg} 120$ e com a carbonila de Arg79, enquanto a hidroxila em C-3 do ligante interagiu por ligação de hidrogênio com a carbonila de Ile523. No complexo de 1DIY com a orientação 2 de AU foram observadas interações por ligação de hidrogênio do carboxilato do ligante com o grupo amida da cadeia lateral de Gln358, com a hidroxila de Ser353 e com água, enquanto a hidroxila em C-3 do ligante interagiu por ligação de hidrogênio com a hidroxila de fenol de Tyr385. Em ambos os complexos da orientação 2 de AU com 1DIY e 2OYE foi observada a presença de moléculas de água próximas ao carboxilato do ligante, mas apenas o complexo formado com $2 \mathrm{OYE}$ indicou a presença de água próxima à hidroxila em C-3.

Considerando que nos quatro complexos mencionados não houve saída do ligante do sítio durante os 15,2 ns de simulação e que as interações por ligação de hidrogênio ocorrem em número e estabilidade variada, não é possível definir qual é a orientação mais favorável de AU no sítio de COX-1.

\section{Complexos de AU com COX-2 provenientes da DM}

Conforme a Tabela 2, no complexo de 4COX com a orientação 1 ' foram observadas interações por ligação de hidrogênio entre as hidroxilas do ligante e de Ser353 e entre o carboxilato do ligante e as hidroxilas de fenol de Tyr348 e Tyr385. Com a orientação 1, foram observadas interações por ligação de hidrogênio do grupo carboxilato do ligante com água, com o grupo guanidina de Arg120 e com a carbonila de Val523 através de uma molécula de água. A hidroxila em C-3 do ligante interagiu com a carbonila de Val99 (interação 
Tabela 2. Interações por ligação de hidrogênio dos complexos de AU com COX-1 e COX-2, provenientes da DM, e $\Delta \mathrm{G}_{\text {bind }}\left(\mathrm{Kcal}_{\text {mol }}{ }^{-1}\right) \mathrm{calculados}_{\text {pelo }} \mathrm{AutoDock} 4$

\begin{tabular}{|c|c|c|c|c|}
\hline $\begin{array}{l}\text { Orientação de } \mathrm{AU}-\mathrm{PDB} \\
\Delta \mathrm{G}_{\text {bind }} \text { redocking }\left(\mathrm{Kcal} \mathrm{mol}^{-1}\right)\end{array}$ & $\begin{array}{l}\text { Interação por ligação } \\
\text { de hidrogênio }\end{array}$ & $\begin{array}{c}\text { Distância } \\
\text { H“A ( }(\AA)\end{array}$ & $\begin{array}{l}\text { Ângulo } \\
\mathrm{HÂY} \\
\text { obs }\end{array}$ & $\begin{array}{l}\text { Ângulo } \\
\mathrm{HÂY} \\
\text { prev }\end{array}$ \\
\hline Orientação 1 - 1DIY (COX-1) -12,68 & 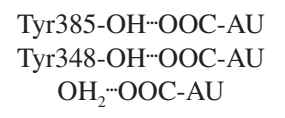 & $\begin{array}{l}1,7 \\
1,6 \\
1,9\end{array}$ & $\begin{array}{c}129,7^{\circ} \\
116,3^{\circ} \\
90,9^{\circ}\end{array}$ & $\begin{array}{l}120^{\circ} \\
120^{\circ} \\
120^{\circ}\end{array}$ \\
\hline Orientação 2 - 1DIY (COX-1) -12,09 & 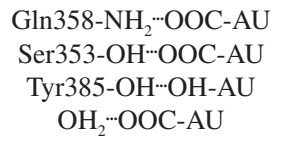 & $\begin{array}{l}1,9 \\
1,8 \\
1,9 \\
1,6\end{array}$ & $\begin{array}{l}138,6^{\circ} \\
114,4^{\circ} \\
116,4^{\circ} \\
117,7^{\circ}\end{array}$ & $\begin{array}{c}120^{\circ} \\
120^{\circ} \\
109,5^{\circ} \\
120^{\circ}\end{array}$ \\
\hline Orientação 2 - 2OYE (COX-1) -10,86 & $\begin{array}{c}\mathrm{Arg} 79-\mathrm{NH}_{2} \cdots \mathrm{OH}_{2} \\
\mathrm{OH}_{2} \cdots \mathrm{OOC}-\mathrm{AU} \\
\mathrm{Arg} 120-\mathrm{NH}_{2} \cdot \mathrm{OH}_{2} \\
\mathrm{OH}_{2} \cdots \mathrm{OOC}-\mathrm{AU} \\
\mathrm{Arg} 79-\mathrm{C}=\mathrm{O} \cdots \mathrm{H}_{2} \mathrm{O} \\
\mathrm{OH}_{2} \cdots \mathrm{OOC}-\mathrm{AU} \\
\text { Ile523-C=O-*HO-AU }\end{array}$ & $\begin{array}{l}2,0 \\
1,8 \\
1,8 \\
1,9 \\
1,9 \\
1,9 \\
1,8\end{array}$ & $\begin{array}{c}126,9^{\circ} \\
129,5^{\circ} \\
91,2^{\circ} \\
93,0^{\circ} \\
131,6^{\circ} \\
93,0^{\circ} \\
131,5^{\circ}\end{array}$ & $\begin{array}{c}109,5^{\circ} \\
120^{\circ} \\
109,5^{\circ} \\
120^{\circ} \\
120^{\circ} \\
120^{\circ} \\
120^{\circ}\end{array}$ \\
\hline Orientação 1 - 2OYE (COX-1) -10,56 & 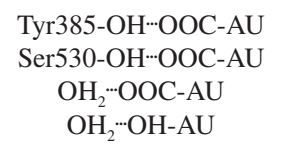 & $\begin{array}{l}1,7 \\
2,0 \\
2,2 \\
1,8\end{array}$ & $\begin{array}{c}148,5^{\circ} \\
79,1^{\circ} \\
152,8^{\circ} \\
86,9^{\circ}\end{array}$ & $\begin{array}{c}120^{\circ} \\
120^{\circ} \\
120^{\circ} \\
109,5^{\circ}\end{array}$ \\
\hline Orientação 2 - 4COX (COX-2) -10,79 & 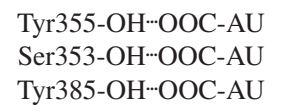 & $\begin{array}{l}2,0 \\
1,6 \\
1,9\end{array}$ & $\begin{array}{l}84,2^{\circ} \\
147,7^{\circ} \\
104,6^{\circ}\end{array}$ & $\begin{array}{l}120^{\circ} \\
120^{\circ} \\
120^{\circ}\end{array}$ \\
\hline Orientação 1' - 4COX (COX-2) -12,55 & 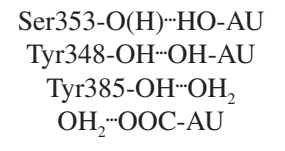 & $\begin{array}{l}2,1 \\
1,9 \\
2,0 \\
2,2\end{array}$ & $\begin{array}{l}85,0^{\circ} \\
118,5^{\circ} \\
109,7^{\circ} \\
114,5^{\circ}\end{array}$ & $\begin{array}{c}109,5^{\circ} \\
109,5^{\circ} \\
109,5^{\circ} \\
120^{\circ}\end{array}$ \\
\hline Orientação 1 - 4COX (COX-2) -12,87 & 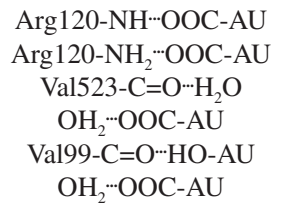 & $\begin{array}{l}1,8 \\
2,0 \\
1,6 \\
2,3 \\
2,2 \\
2,1\end{array}$ & $\begin{array}{c}104,4^{\circ} \\
108,1^{\circ} \\
116,1^{\circ} \\
108,8^{\circ} \\
85,2^{\circ} \\
104,9^{\circ}\end{array}$ & $\begin{array}{l}120^{\circ} \\
120^{\circ} \\
120^{\circ} \\
120^{\circ} \\
120^{\circ} \\
120^{\circ}\end{array}$ \\
\hline
\end{tabular}

HÂY ${ }_{\text {obs }}$ e HÂY ${ }_{\text {prev }}$ referem-se, respectivamente, aos ângulo HÂY observado e previsto conforme a hibridação do átomoA, sendo que H (átomo de hidrogênio), A (átomo aceptor) e Y (átomo ligado por covalência ao aceptor).

fraca, conforme o ângulo HÂY) e com uma molécula de água. Neste complexo, o ligante distanciou-se muito do ápice do sítio e interagiu com os resíduos da superfície proteica Va199, Trp100 e Val103, o que é uma desvantagem para a inibição da enzima e indica uma possível saída do ligante do sítio ativo durante a simulação. No complexo da orientação 2 com 4COX foram observadas interações por ligação de hidrogênio do carboxilato do ligante com as hidroxilas de Tyr355 (interação fraca, conforme o ângulo HÂY) e Ser353 e da hidroxila em C-3 do ligante com a hidroxila de fenol de Tyr385. Foi verificada a presença de moléculas de água próximas ao ligante na região do grupo carboxilato, que se aproximou da entrada da cavidade de seletividade (Ser353).

Comparando-se os resultados obtidos nos redockings de COX-2 com AO e AU, nota-se que a orientação 1 desses ligantes se afastou do sítio ativo em ambos os complexos. Assim, podem ser considerados pouco estáveis os complexos de COX-2 com AO e AU mantidos na orientação 1 dentro do sítio ativo.

\section{Redocking de AO e AU com monômeros de isoformas COX provenientes de complexos da DM}

Nos redockings de AO e AU com as estruturas dos monômeros obtidas dos complexos de 15,2 ns, os ligantes sobrepuseram-se satisfatoriamente aos ligantes originais dos complexos, o que permitiu relacionar os valores de $\Delta \mathrm{G}_{\text {bind }}$ calculados pelo AutoDock 4 aos complexos equilibrados pela DM. Entretanto, esses valores, inseridos nas Tabelas 1 e 2, mostraram que $\mathrm{AO}$ e AU não são seletivos para COX-2 e que não é possível determinar qual é a orientação do ligante mais favorável para cada isoforma, devido às limitações da função de pontuação do AutoDock 4. Cabe lembrar que as metodologias de docking não são adequadas para a previsão de valores acurados de $\Delta \mathrm{G}_{\text {bind }}$, embora o sejam para a previsão de interações, principalmente se associadas à DM. Dessa forma, torna-se importante avaliar as energias de interação dos complexos por métodos mais apropriados, tais como perturbação de energia livre (FEP - free energy perturbation), ${ }^{41}$ por exemplo.

\section{CONSIDERAÇÕES FINAIS}

Os resultados provenientes da DM mostraram que os principais resíduos das isoformas COX que interagem por ligações de hidrogênio estáveis com os ácidos oleanólico e ursólico são Arg120, Tyr355, Ser353, Tyr385 e Ser530, comumente relatados em artigos de docking e DM de inibidores diversos com COX, seletivos para COX-2 ou não seletivos. Observou-se, também, a importância das moléculas de água para a estabilização dos grupos polares de $\mathrm{AO}$ e AU em todos os complexos, mediando interações por ligação de hidrogênio com os resíduos de aminoácidos, inclusive. Pode-se afirmar que a orientação 1 de ambos os ligantes no sítio ativo de COX-2 é energeticamente desfavorável quando comparada às orientações 1' e 2; logo, AO interage com COX-2 com orientação do tipo 2, o que talvez não ocorra com $\mathrm{AU}$ porque este ligante pode interagir com 


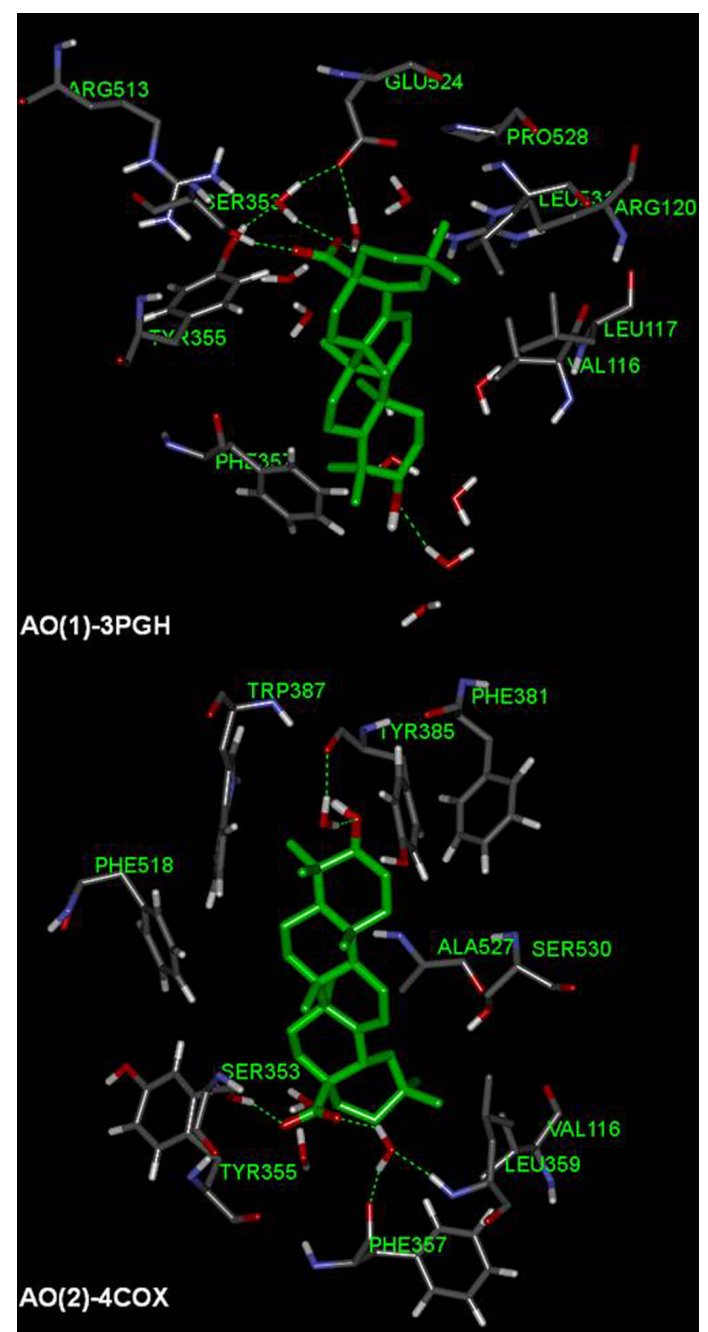

Figura 5. Orientações 1 e 2 do ácido oleanólico no sítio ativo de COX-2, obtidas após 15,2 ns de simulação por dinâmica molecular desse triterpenoide com as estruturas cristalográficas $3 P G H$ e $4 \mathrm{COX}$, respectivamente. Considerando que os resíduos Tyr355 e Ser353 estão presentes na base do sítio ativo, e que o resíduo Tyr385 está presente no ápice, nota-se que a orientação 1 (figura superior) está afastada do sítio ativo ao fim da trajetória de 15,2 $n s$, ao contrário da orientação 2 (figura inferior). As interações por ligação de hidrogênio estão explicitadas em verde e apenas os resíduos próximos ao ligante (distância máxima de $4 \AA$ ) são apresentados, mas alguns foram removidos para melhor visualização do complexo. Figura produzida com auxílio do programa Discovery Studio Visualizer versão $2.5 .5^{26}$

COX-2 através das orientações 1' ou 2.

Em relação aos complexos de COX-1, merece destaque o fato de os complexos da orientação 1 de AU com 2OYE e 1DIY, diferentes entre si na estrutura obtida pelo docking com monômero rígido, terem convergido para interações semelhantes durante a simulação, o que demonstra a limitação do docking com receptor rígido e a necessidade de se combinar docking e DM em estudos de complexos receptorligante. Em alguns complexos formados com ambas as isoformas, os grupos carboxilato dos ligantes, passíveis de modificação por semissíntese, aproximaram-se de resíduos do bolso de seletividade, mais acessível em COX-2, o que é importante para o planejamento de inibidores COX-2-seletivos. Assim, os resultados obtidos neste trabalho forneceram subsídios importantes para a proposição do mecanismo de inibição das isoformas ciclo-oxigenases, principalmente a COX-2, pelos triterpenoides ácidos oleanólico e ursólico.

\section{MATERIAL SUPLEMENTAR}

Está disponibilizado em http://quimicanova.sbq.org.br, na forma de arquivo .pdf, com acesso livre.

\section{AGRADECIMENTOS}

Às agências CNPq, CAPES, FAPEMIG e FAPERJ.

\section{REFERÊNCIAS}

1. Botting, R. M.; J. Therm. Biol. 2006, 31, 208.

2. Yaqub, S.; Henjum, K.; Mahic, M.; Jahnsen, F. L.; Aandahl, E. M.; Bjornbeth, B. A.; Tasken, K.; Cancer Immunol. Immunother. 2008, 57, 813.

3. Kurumbail, R. G.; Stevens, A. M.; Glerse, J. K.; Mcdonald, J. J.; Stegeman, R. A.; Pak, J. Y.; Gildehaus, D.; Miyashiro, J. M.; Penning, T. D.; Seibert, K.; Isakson, P. C.; Stallings, W. C.; Nature 1996, 384, 644.

4. Limongelli, V.; Bonomi, M.; Marinelli, L.; Gervasio, F. L.; Cavalli, A.; Novellino, E.; Parrinello, M.; Proc. Natl. Acad. Sci. U.S.A. 2010, 107, 5411.

5. Kang, P.; Dalvie, D.; Smith, E.; Renner, M.; Chem. Res. Toxicol. 2009, 22, 106 .

6. Burke, A.; Smyth, E.; Fitzgerald, G. A. Em Goodman \& Gilman: As Bases Farmacológicas da Terapêutica; Brunton, L. L.; Lazo, J. S.; Parker, K. L., eds.; McGraw-Hill: Rio de Janeiro, 2006, cap. 26.

7. Liu, J.; J. Ethnoph. 2005, 100, 92.

8. Ringbom, T.; Segura, L.; Noreen, Y.; Perera, P.; Bohlin, L.; J. Nat. Prod. 1998, 61, 1212.

9. Berman, H. M.; Westbrook, J.; Feng, Z.; Gilliland, G.; Bhat, T. N.; Weissig, H.; Shindyalov, I. N.; Bourne, P. E.; Nucleic Acids Res. 2000, 28, 235.

10. Picot, D.; Loll, P. J.; Garavito, R. M.; Nature 1994, 367, 243.

11. Malkowski, M. G.; Ginell, S. L.; Smith, W. L.; Garavito, R. M.; Science 2000, 289, 5486 .

12. Harman, C. A.; Turman, M. V.; Kozak, K. R.; Marnett, L. J.; Smith, W. L.; Garavito, R. M.; J. Biol. Chem. 2001, 27, 28096.

13. Rimon, G.; Sidhu, R. S.; Lauver, D. A.; Lee, J. Y.; Sharma, N. P.; Yuan, C.; Frieler, R. A.; Trievel, R. C.; Lucchesi, B. R.; Smith, W. L.; Proc. Natl. Acad. Sci. U.S.A. 2010, 107, 28.

14. Rowlinson, S. W.; Kiefer, J. R..; Prusakiewicz, J. J.; Pawlitz, J. L.; Kozak, K. R.; Kalgutkar, A. S.; Stallings, W. C.; Kurumbail, R. G.; Marnett, L. J.; J. Biol. Chem. 2003, 14, 45763.

15. Guex, N.; Peitsch, M.; Schwede, T.; Diemand, A.; DeepView/SwissPdbViewer: v.4.0.1; The Swiss Institute of Bioinformatics, USA, 2008.

16. Sekhar, P. N.; Reddy, L. A.; Maeyer, M.; Kumar, K. P.; Srinivasulu, Y. S.; Sunitha, M. S. L.; Sphoorthi, I. S. N.; Jayasree, G.; Rao, A. M.; Kothekar, V. S.; Narayana, P. V. B. S; Kishor, P. B. K.; J. Mol. Graphics Modell. 2009, 28, 313.

17. Deppmeier, B. J.; Driessen, A. J.; Hehre, W. J.; Johnson, J. A.; Klunzinger, P. E.; Watanabe, M.; Yu, J.; PC Spartan Pro v6.0.6; Wavefunction Inc., USA, 2000.

18. Dewar, M. J. S.; Zoebisch, E. G.; Healy, E. F.; Stewart, J. J. P.; J. Am. Chem. Soc. 1985, 107, 3902.

19. Sanner, M. F.; Huey, R.; Dallakyan, S.; Karnati, S.; Lindstrom, W.; Morris, G. M.; Norledge, B.; Omelchenko, A.; Stoffler, D.; Vareille, G.; AutoDockTools v1.5.2 revision 2; Molecular Graphics Laboratory, The Scripps Research Institute, USA, 2008.

20. Gasteiger, J.; Marsili, M.; Tetrahedron 1980, 36, 3219.

21. Morris, G. M.; Huey, R.; Lindstrom, W.; Sanner, M. F.; Belew, R. K.; Goodsell, D. S.; Olson, A. J.; J. Comput. Chem. 2009, 30, 2785.

22. Mashhadi, H. R.; Shanechi, H.M.; Lucas, C.; IEEE Trans. Power Syst. 2003, 18, 1181. 
23. Huey, R.; Morris, G. M.; Olson, A. J.; Goodsell, D. S.; J. Comput. Chem. 2007, 28, 1145.

24. Jain, A. N.; J. Med. Chem. 2003, 46, 499.

25. Gani, O. A. B. S. M.; Chem. Biol. Drug Des. 2007, 70, 360.

26. Accelrys Software Inc.; Discovery Studio Modeling Environment, Release 2.5; San Diego: Accelrys Software Inc., 2009.

27. Hess, B.; Kutzner, C.; van der Spoel, D.; Lindahl, E.; J. Chem. Theory Comput. 2008, 4, 435.

28. Schuler, L. D.; Daura, X.; van Gunsteren, W. F.; J. Comput. Chem. 2001, $22,1205$.

29. Daura, X.; Mark, A. E.; van Gunsteren, W. F.; J Comput. Chem. 1998, 19,535 .

30. Schüttelkopf, A. W.; van Aalten, D. M. F.; Acta Crystallogr., Sect. D: Biol. Crystallogr. 2004, 60, 1355.

31. Frisch, M. J.; Trucks, G. W.; Schlegel, H. B.; Scuseria, G. E.; Robb, M. A.; Cheeseman, J. R.; Montgomery Jr., J. A.; Vreven, T.; Kudin, K. N.; Burant, J. C.; Millam, J. M.; Iyengar, S. S.; Tomasi, J.; Barone, V.; Mennucci, B.; Cossi, M.; Scalmani, G.; Rega, N.; Petersson, G. A.; Nakatsuji, H.; Hada, M.; Ehara, M.; Toyota, K.; Fukuda, R.; Hasegawa, J.; Ishida, M.; Nakajima, T.; Honda, Y.; Kitao, O.; Nakai, H.; Klene, M.; Li, X.; Knox, J. E.; Hratchian, H. P.; Cross, J. B.; Adamo, C.; Jaramillo, J.; Gomperts, R.; Stratmann, R. E.; Yazyev, O.; Austin, A. J.; Cammi, R.; Pomelli, C.; Ochterski, J. W.; Ayala, P. Y.; Morokuma, K.; Voth, G. A.; Salvador, P.; Dannenberg, J. J.; Zakrzewski, V. G.; Dapprich, S.; Daniels, A. D.; Strain, M. C.; Farkas, O.; Malick, D. K.; Rabuck, A.
D.; Raghavachari, K.; Foresman, J. B.; Ortiz, J. V.; Cui, Q.; Baboul, A. G.; Clifford, S.; Cioslowski, J.; Stefanov, B. B.; Liu, G.; Liashenko, A.; Piskorz, P.; Komaromi, I.; Martin, R. L.; Fox, D. J.; Keith, T.; Al-Laham, M. A.; Peng, C. Y.; Nanayakkara, A.; Challacombe, M.; Gill, P. M. W.; Johnson, B.; Chen, W.; Wong, M. W.; Gonzalez, C.; Pople, J. A.; Gaussian 03 Revision-B.03; Gaussian, Inc., USA, 2003.

32. Berendsen, H. J. C.; Grigera, J. R.; Straatsma, T. P.; J. Phys. Chem. 1987, 91, 6269.

33. Namba, A. M.; Silva, V. B.; Silva, C. H. T. P.; Ecl. Quim. 2008, 33, 13.

34. Hess, B.; Bekker, H.; Berendsen, H. J. C.; Fraaije, J. G. E. M.; J. Comput. Chem. 1997, 18, 1463.

35. Darden, T.; York, D.; Pedersen, L.; J. Chem. Phys. 1993, 98, 10089.

36. Berendsen, H. J. C.; Postma, J. P. M.; van Gunsteren, W. F.; DiNola, A.; Haak, J. R.; J. Chem. Phys. 1984, 81, 3684.

37. Luck, W. A. P. Em The Hydrogen Bond: Recent developments in theory and experiments; Schuster, P.; Zundel, G.; Sandorfy, C., eds.; NorthHolland: Amsterdam, 1976, cap. 11.

38. Plewczynski, D.; Lazniewski, M.; Augustyniak, R.; Ginalski, K.; J. Comput. Chem. 2011, 32, 742.

39. Palomer, A.; Pérez, J. J.; Navea, S.; Llorens, O.; Pascual, J.; García, L.; Mauleón, D.; J. Med. Chem. 2000, 43, 2280.

40. Sai Ram, K. V. V. M.; Rambabu, G.; Sarma, J. A. R. P.; Desiraju, G. R.; J. Chem. Inf. Model. 2006, 46, 1784.

41. Douut, J. P.; Weber, J.; Computer-Aided Molecular Design - Theory and Applications, Academic Press: Londres, 1997. 